\title{
Ureteral metastasis from a HER2-enriched breast cancer: a rare case report
}

\author{
Jun Zhou ${ }^{1}$, Jian Liu ${ }^{1}$, Aizhai Xiang ${ }^{1}$, Yanna Shan ${ }^{2}$, Jingjing Xiang ${ }^{3}$, Wei Wang ${ }^{3}$, Haidong Cui ${ }^{1}$ \\ ${ }^{1}$ Department of Breast Surgery, ${ }^{2}$ Department of Radiology, ${ }^{3}$ Department of Pathology, Affiliated Hangzhou First People's Hospital, Zhejiang \\ University School of Medicine, Hangzhou, China \\ Correspondence to: Haidong Cui. Department of Breast Surgery, Affiliated Hangzhou First People's Hospital, Zhejiang University School of Medicine, \\ 261 Huansha Road, Hangzhou, China. Email: cuihaidong79@163.com.
}

\begin{abstract}
Ureteral metastasis from breast cancer (BC) is very rare, and only a few cases have been reported. We report the first patient with ureteral involvement from human epidermal receptor 2 (HER2) enriched metastatic BC. A 51-year-old woman with HER2-enriched metastatic BC with liver metastasis was diagnosed at her first visit, achieving complete tumor regression by chemotherapy, anti-HER2 treatment, modified mastectomy and radiotherapy. After 1 year, she complained light left flank pain for 1 month, with an elevated cancer antigen 15-3 (CA15-3) level in blood. Computed tomography showed a left proximal ureteral lesion causing ureterectasis and hydronephrosis. A ureteroscope-guided biopsy of the ureteral lesion revealed poorly differentiated carcinoma from metastatic BC. Diagnosing ureter metastasis from BC were established by histopathology and immunohistochemistry. The flank pain and ureteral lesion were absolutely relieved after chemotherapy and anti-HER2 treatment, and CA15-3 level decreased to normal. Regular follow-up examinations every 3 months are performed at our outpatient clinic. With a 20 months follow-up, there has been no further progression up to now. Ureteral metastasis of BC shows nonspecific symptoms, and it is important to recognize this unusual manifestation so that timely appropriate treatment can be initiated in order to better prognosis. Chemotherapy plus anti-HER2 treatment are most effective for hepatic and ureteral metastasis from BC.
\end{abstract}

Keywords: Breast cancer (BC); human epidermal receptor 2 (HER2); ureteral metastasis; diagnosis; treatment; case report

Submitted Feb 15, 2020. Accepted for publication Jun 23, 2020.

doi: $10.21037 /$ tcr-20-1047

View this article at: http://dx.doi.org/10.21037/tcr-20-1047

\section{Introduction}

Breast cancer (BC), the most prevalent malignancy among adult women, commonly metastasizes to distant sites such as bone, liver, lung, and brain (1). BC metastasizing to the ureter is very rare, and only 4 cases have been reported in the twenty-first century (2-5). Herein, we report a first case of human epidermal receptor 2 (HER2) enriched BC that metastasized to the ureter. We present the following case in accordance with the CARE reporting checklist (6).

\section{Case presentation}

A 51-year-old woman with complaints of a left breast lump was admitted to the department of Breast Surgery of Hangzhou First People's Hospital in January 2017. The patient had no previous specific disease or family history of breast and ovarian cancer. Both ultrasonography (US) and magnetic resonance imaging revealed a solid mass $(51 \mathrm{~mm} \times 60 \mathrm{~mm} \times 31 \mathrm{~mm})$ in the left breast and enlarged lymph nodes in the ipsilateral axilla. Core needles biopsy revealed estrogen receptor (ER)-negative, progesterone receptor $(\mathrm{PgR})$-negative, and HER2-positive invasive ductal carcinoma. Abdominal computed tomography (CT) revealed multiple metastatic nodules in the liver, with an elevated cancer antigen 15-3 (CA15-3) level of $199.8 \mathrm{U} / \mathrm{mL}$ (normal value $<31 \mathrm{U} / \mathrm{mL}$ ). The genetic testing revealed that she wasn't a BRCA1 and BRCA2 mutation carrier. 

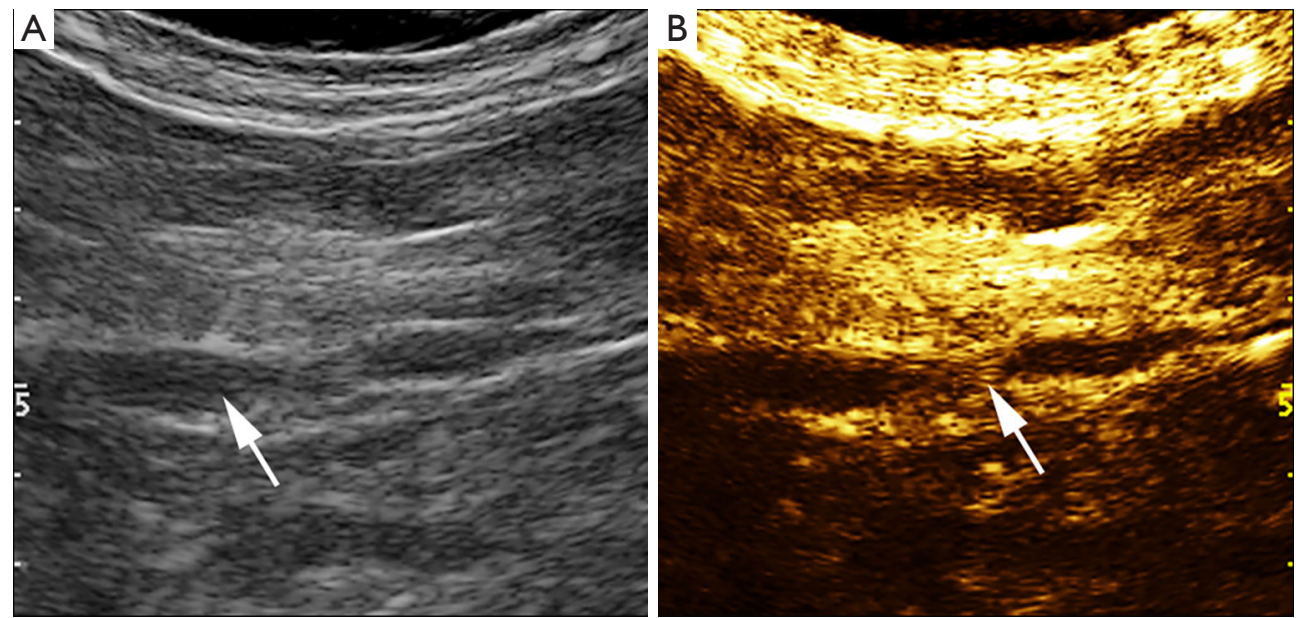

Figure 1 Ultrasound contrast showing a ureteral lesion (B, arrow) with ureteral dilatation (A, arrow).
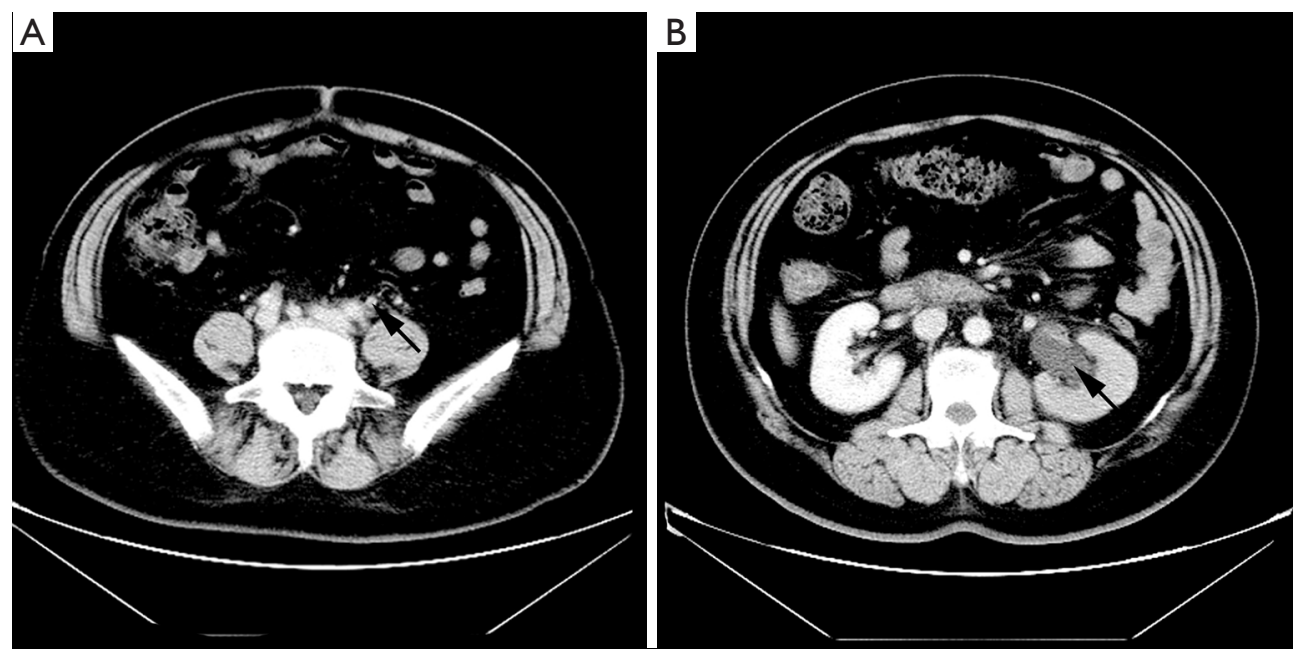

Figure 2 Ureteral computed tomography showing a left ureteral lesion (A, arrow) with hydronephrosis (B, arrow).

Further screening found no other metastases. The patient subsequently received 8 cycles of TCbH chemotherapy (docetaxel at $75 \mathrm{mg} / \mathrm{m}^{2}$, carboplatin at AUC 6, trastuzumab at a dose of $8 \mathrm{mg} / \mathrm{kg}$ initially, followed by $6 \mathrm{mg} / \mathrm{kg}$ intravenously every 3 weeks). Partial response in the left breast and complete response in the liver were clinically achieved, and the CA15-3 level decreased to $23.0 \mathrm{U} / \mathrm{mL}$ after chemotherapy. The patient underwent left modified mastectomy and axillary lymph node dissection followed by radiotherapy. Histopathology revealed $1 \mathrm{~mm}$ invasive ductal and $18 \mathrm{~mm}$ high grade ductal carcinoma in situ with axillary lymph node metastasis (1/5) and Miller-Payne grading 4. The tumor was ER, PgR negative, and HER2 positive.
The patient was referred to the urology clinic in June 2018 with complaining of slight left flank pain for 1 month. As shown in Figure 1 and 2, both abdominal enhanced CT and contrast-enhanced ureteral US revealed a left proximal ureteral lesion causing ureterectasis and hydronephrosis. At that time her CA15-3 level increased to $40.9 \mathrm{U} / \mathrm{mL}$. A ureteroscope-guided biopsy of the left ureteral lesion revealed poorly differentiated carcinoma from metastatic $\mathrm{BC}$, the immunohistochemistry of tumor cells was positive for HER2, GATA-3, CK7, P53, Ki67 (+30\%), and negative for ER, PgR, CK5/6, CK 20, PAX8, P63 (Figure 3). She received $\mathrm{PH}$ chemotherapy (paclitaxel at $80 \mathrm{mg} / \mathrm{m}^{2}$, and trastuzumab at a dose of $4 \mathrm{mg} / \mathrm{kg}$ initially, followed by 

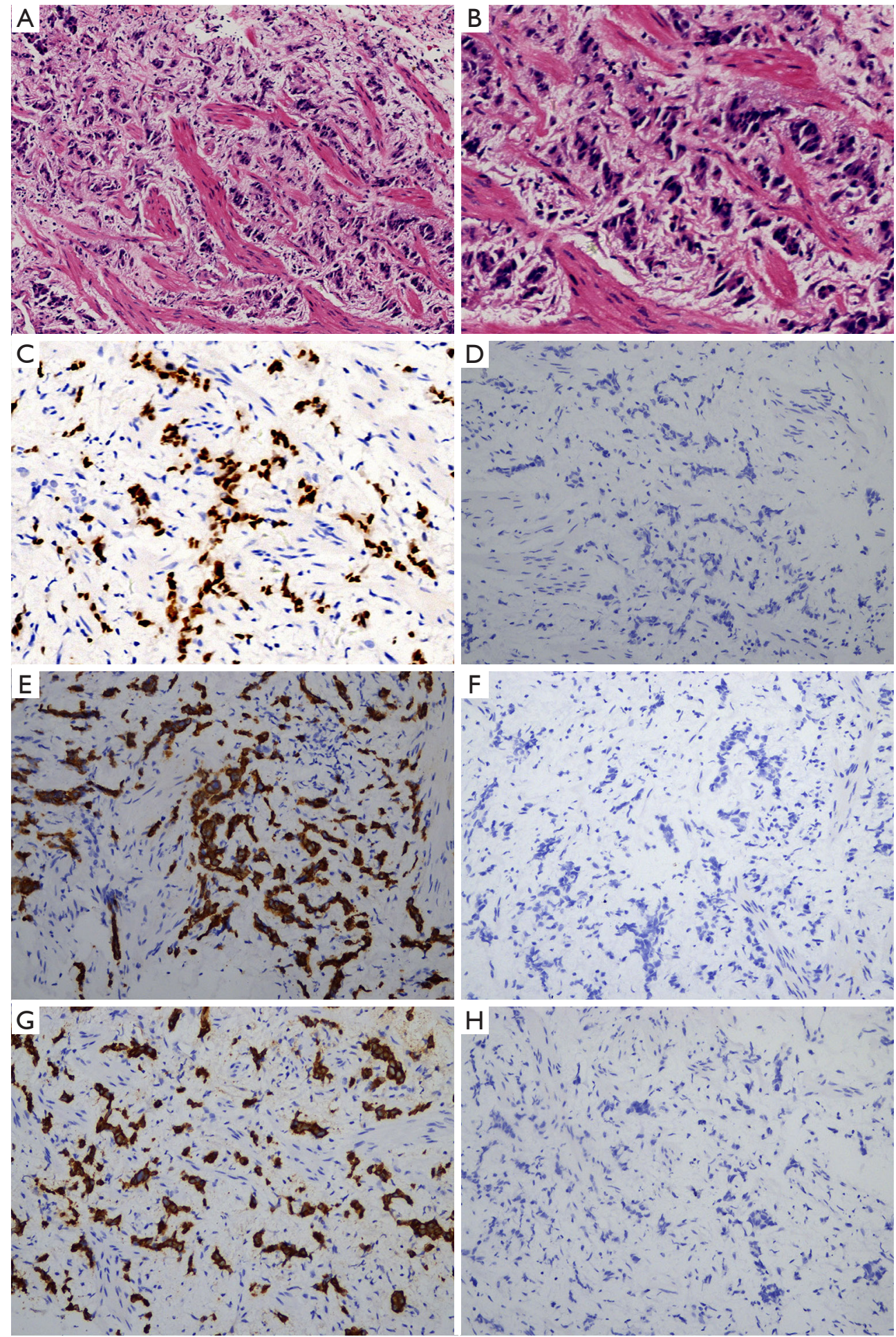

Figure 3 Pathological features of the involved ureter: the poorly differentiated carcinoma in the fibers and smooth muscle of the left ureter. Hematoxylin-eosin staining $\times 10, \times 20(\mathrm{~A}, \mathrm{~B})$, and it was positive for (E) HER2, (C) GATA-3, (G) CK7, P53, Ki67 (+30\%), and negative for ER, PgR, (D) CK5/6, (F) CK 20, (H) PAX8, P63 (immunohistochemical stain, ×200). 


\section{Timeline of History}

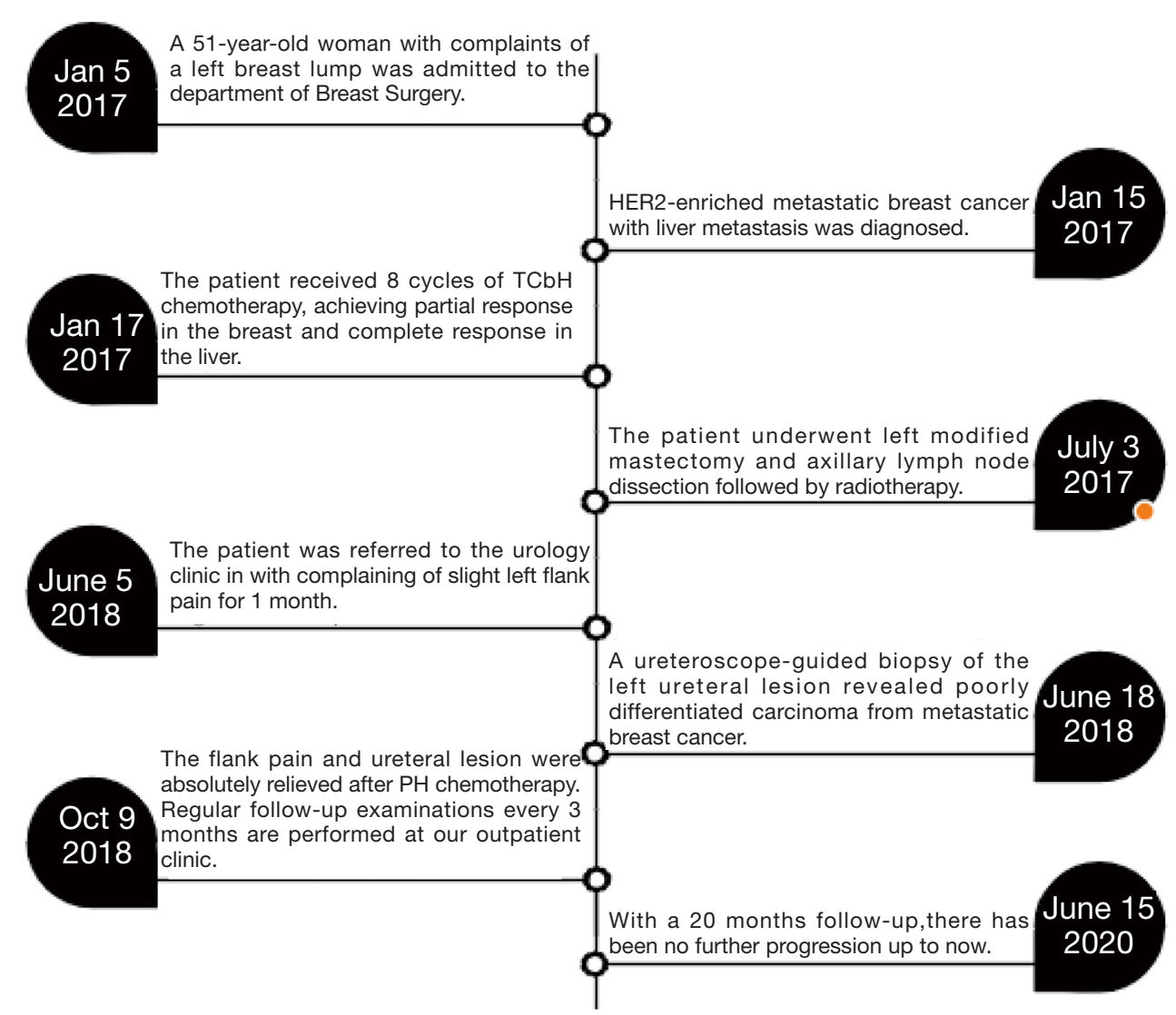

Figure 4 Case report timeline.

$2 \mathrm{mg} / \mathrm{kg}$ intravenously weekly). The flank pain disappeared after 5 cycles, and her CA15-3 level decreased to normal. CT showed that the ureteral lesion had been too small to observe. Ureterectasis and hydronephrosis were relieved at the end of 10 cycles, without adverse and unanticipated events. The patient is currently being followed up, and there has been no further progression up to now (Figure 4). Written informed consent was obtained from the patient for publication of this manuscript and any accompanying images.

\section{Discussion}

A new literature review reported that 265 patients with ureteral metastasis from other primary cancers, including prostate, bladder, breast, colorectal cancer, and lymphoma, were documented (7). The first case of ureteral metastasis from primary BC was reported in 1929 (8), and since then, 40 cases has been reported (7): 36 cases diagnosed based on radiological findings or autopsy (9) and only 4 cases confirmed base on pathological examination (2-5).

It was difficult to make a differential diagnosis with other celiac diseases. An increase in carcinoembryonic antigen or CA15-3 indicated the progression of BC (3). The most common symptom of ureteral metastasis was slight flank or abdominal pain caused by ureteral obstruction, followed by oliguria and hematuria. Metastasis mostly occurred in the lower ureter (7), but proximal ureteral metastasis was found in this patient. Urinary examinations are required for BC patients with a complaining of abdominal or flank pain. In our case, hydronephrosis, ureterectasis or intraureteral mass were detected by US or CT, and a ureteroscope was used to locate the lesions and obtain pathological tissue.

To the best of our knowledge, this was the first reported 
case that a HER2-enriched BC that metastasized to the ureter. In the literature, the molecular subtype of most ureteral metastatic BCs was $\mathrm{ER}(+), \operatorname{PgR}(+)$, and HER-2(-) (10). The median interval time from BC onset to diagnosis of ureter metastasis was 180 months and the survival time was only 11 months (7). Endocrine therapy and chemotherapy are common systemic therapy for patients with multiple metastases, and segmental ureteral resection and radiotherapy are applied in patients with isolated ureteral involvement $(2-4,11)$. Chemotherapy plus anti-HER2 treatment are effective for metastatic hepatic and ureteral lesions in our patient.

In our case, some useful methods make its diagnosis and treatment rational, including CA15-3 in the blood, enhanced CT, enhanced ureteral US, ureteroscope-guided biopsy chemotherapy, and anti-her-2 therapy. However, we may make extra improvements, such as intravenous urography, retrograde urography, segmental ureteral resection, radical nephroureterectomy, radiotherapy or a combination of these treatments.

In conclusion, metastatic involvement of the ureter should be considered as an alternative diagnosis in patients with a history of $\mathrm{BC}$, complaints of vague urinary symptoms, and unexplained back or flank pain.

\section{Acknowledgments}

Funding: This work was supported by Hangzhou Science and Technology Bureau (No. 20170533B26) and Zhejiang Provincial Program for Medicine and Health youth talents (No. 2019RC242).

\section{Footnote}

Reporting Checklist: The authors have completed the CARE reporting checklist. Available at http://dx. doi. org/10. 21037/tcr-20-1047

Peer Review File: Available at http://dx. doi. org/10. 21037/ tcr-20-1047

Conflicts of Interest: All authors have completed the ICMJE uniform disclosure form (available at http://dx. doi. org/10. 21037/tcr-20-1047). The authors have no conflicts of interest to declare.
Ethical Statement: The authors are accountable for all aspects of the work in ensuring that questions related to the accuracy or integrity of any part of the work are appropriately investigated and resolved. All procedures performed in studies involving human participants were in accordance with the Declaration of Helsinki (as revised in 2013). Written informed consent was obtained from the patient for publication of this manuscript and any accompanying images.

Open Access Statement: This is an Open Access article distributed in accordance with the Creative Commons Attribution-NonCommercial-NoDerivs 4.0 International License (CC BY-NC-ND 4.0), which permits the noncommercial replication and distribution of the article with the strict proviso that no changes or edits are made and the original work is properly cited (including links to both the formal publication through the relevant DOI and the license). See: https://creativecommons.org/licenses/by-nc-nd/4.0/.

\section{References}

1. Gerratana L, Fanotto V, Bonotto M, et al. Pattern of metastasis and outcome in patients with breast cancer. Clin Exp Metastasis 2015;32:125-33.

2. Hudolin T, Nola N, Milas I, et al. Ureteral metastasis of occult breast cancer. Breast 2004;13:530-2.

3. Mondaini N, Giubilei G, Nesi G, et al. Carcinoma of the breast metastatic to the ureter seven years later. Int J Urol 2005;12:763-4.

4. Zhou ZH, Sun LJ, Zhang GM. Ureter - an unusual site of breast cancer metastasis: A case report. World J Clin Cases 2019;7:3347-52.

5. Pastore AL, Pelleschi G, Tubaro A, et al. Synchronous urinary tract metastases from breast cancer. Urologia 2009;76:66-7.

6. DS R, MS B, GS K, et al. CARE guidelines for case reports: explanation and elaboration document. J Clin Epidemiol 2017;89:218-35.

7. Hu J, Deng J, Guo J, et al. Ureteral involvement by metastatic malignant disease. Clin Exp Metastasis 2019;36:499-509.

8. Glas R. A contribution to primary and metastatic cancer of ureters. Wien Klin Wochenschr 1926;39:1145-9.

9. Caskey CI, Scatarige JC, Fishman EK. Distribution of 
metastases in breast carcinoma: CT evaluation of the abdomen. Clin Imaging 1991;15:166-71.

10. Feun LG, Drelichman A, Singhakowinta A, et al. Ureteral obstruction secondary to metastatic breast carcinoma. Cancer 1979;44:1164-71.

Cite this article as: Zhou J, Liu J, Xiang A, Shan Y, Xiang J, Wang W, Cui H. Ureteral metastasis from a HER2-enriched breast cancer: a rare case report. Transl Cancer Res 2020;9(8):50205025. doi: $10.21037 /$ tcr-20-1047
11. Xiao W, Zheng S, Yang A, et al. Breast cancer subtypes and the risk of distant metastasis at initial diagnosis: a population-based study. Cancer Manag Res 2018;10:5329-38. 